\title{
Small-Scale Farmers' Preference in Adopting Geographical Indications' Code of Practice to Produce Coffee in Indonesia: A Choice Experiment Study
}

\author{
Pandu Laksono ${ }^{1, *}$, Irham ${ }^{2}$, Jangkung Handoyo Mulyo $^{2}$, Any Suryantini ${ }^{2}$, Dwiko Budi Permadi $^{3}$ \\ ${ }^{1}$ Assessment Institute for Agricultural Technology of Papua, Jayapura, Indonesia 99352 \\ ${ }^{2}$ Agricultural Sciences, Faculty of Agriculture, Gadjah Mada University, Yogyakarta, Indonesia, \\ 55281 \\ ${ }^{3}$ Forest Science, Faculty of Forestry, Gadjah Mada University, Yogyakarta, Indonesia, 55281
}

\begin{abstract}
Geographical Indication is a type of collective intellectual property that producers may use to capture the placerelated value expressed in their product which involve the physical and anthropic characteristics of the production area. There is GI's Code of Practice (CoP) that should be adopted by farmers as reference standard to maintain GIs product consistency and definition requirements. Understanding farmer preferences and incorporating them into the development of improvement of GIs' certification schemes is thought to result in more internalized, and thus more efficient standards. This study aims to 1) investigate the small-scale farmers' preferences and the influence of socioeconomics characteristics rejecting GIs' scheme; and 2) develop strategies to increase farmers participation on GIs' scheme. Choice Experiment method and Conditional Logit Model (CLM) were used to estimate preferences of 157 small-scale coffee farmers for accepting GIs' scheme. The findings suggest that premium price, coffee processing, technical assistance, and selling agreement are all GIs' attributes that could increase small-scale farmers' utility. More incentives are required to compensate farmers due to the loss of utility caused by pesticide bans and farm inspection. Based on CLM, the study found that farmers have clear preferences for and against certain aspects of GIs' CoP scheme.
\end{abstract}

\section{Introduction}

According to Neilson et al.[1], the primary objective of GI is to capture the economic benefits of place-related features in production locales, however additional non-economic

${ }^{*}$ Corresponding author: pandulksn@gmail.com 
benefits such as environmental and cultural preservation and social institutional development may also exist. The implementation of Geographical Indication in the coffee sector is expected could assist small farmers to produce coffee with better quality standards, more consistent qualities and be able to demonstrate that there is a link between production characteristics and product quality produced in a GI area [2]. Qualifying producers in the defined region must adhere to predefined production requirements in order to use the GI (subject to third-party verification), includes the requirements for the use of inputs and product processing that are distinct from non-GI standards when GI standards are applied [3].

One of the challenges in establishing GI certification in the coffee industry in Indonesia is a lack of control over the application of GI standards or codes of practices [1]. The MPIG (Masyarakat Perlindungan Indikasi Geografis, or Community of GI Protection), a community-based organization comprising coffee producers, processors, traders, and roasters, is the applicant organization for all registered coffee GIs. MPIG is in charge of implementing GI-based coffee production standards. Farmers must follow the rules or Code of Practice for geographically indicated coffee cultivation as outlined in Buku Persyaratan Indikasi Geografis (Book of Specifications). The quality standard for coffee goods specified in the Geographical Indication Requirements book is the Indonesian National Standard [4].

An effective Standard Operating Procedure, according to Ibnu et al [5], is one that farmers can internalize in their farming system, such that the design of S.O.P, such as in a certification scheme or contract, must be able to take into consideration and comprehend farmers' preferences. It's crucial to recognize and comprehend the taste or location-specific preferences of farmers. Understanding and knowledge about preferences seeks to make certification scheme implementation more effective [6] has a higher or adoptable degree of acceptance [5,7], and can be accepted by farmers [8,9]. It is suggested that the design of partnership and certification programs involve the local community in the development of partnership attributes and certification requirements [10]. Meanwhile, Pirard et al [11] said that the amount to which local community preferences are accommodated in the design of standards and attributes in a scheme influences farmers' motivation to join in a partnership or certification scheme.

Local agricultural communities have so far been underrepresented in the development of partnership or contract models, as well as certification criteria [12]. There have been few studies on how local communities are involved in the development of contract criteria and attributes. The standard design based on farmers' preferences, on the other hand, can be used as a model for strengthening farmers' bargaining power in partnership, certification, and contract programs, which are expected to overcome a number of issues in the future, including low farmer participation and contract violations[13]. Furthermore, in term of Geographical Indication, according to Glatier et al.[14], one of key success for the implementation of GI's scheme is the involvement of local producers in designing code of practice.

The general question in this study is about the preference of coffee farmers in Indonesia for geographical indication certification. To answer this question, two more specific questions are needed, First, which attributes can be effectively modified and also renegotiated? Second, how much change in monetary attributes is required to increase smallholders' willingness to accept the modified scheme, as well as the farmers' socioeconomic characteristics?

The objective of this study is to determine whether smallholder coffee farmers are willing to accept modified coffee production standards based on geographical indication. To accomplish it, we first calculate the specific value of each contract attribute for local farmers. We also investigate the socio-economic aspects that influence local farmers' 
rejecting GIs' scheme. Finally, we will provide strategies to increase small farmers participation on GIs' scheme.

To address the questions problems, this research applies a quantitative approach. The acceptance of a Geographical Indication-based coffee production scheme is assumed to depend on a set of standard production attributes offered to coffee farmers. For policy analysis, we employ the Choice Experiment (CE) method, which is a stated preference method that economically considers the value of non-market or prospective products (in this case, scheme) [15]. The findings of this research could help stakeholders like MPIG and the local government design a coffee production scheme based on Geographical Indications that is more acceptable, adaptive, and effective for smallholders. This is the first attempt, to our knowledge, to apply the $\mathrm{CE}$ technique to assess small coffee farmers' preferences in a Geographical Indication-based coffee production scheme.

The approach and procedure for conducting a choice experiment survey and data analysis will be described in the next section. The results will be presented after which there will be a discussion of the challenges of Geographical Indication-based coffee production schemes and their policy implications. A conclusion is included at the end of the paper.

\section{Literature review}

\subsection{Coffee certification}

Contract is a type of response that is used to address market imperfections such as credit, information, technology transfer, input access, and product markets [13,16-19]. The extent to which smallholders participate in contracts is determined by the market failures they experience and their exposure to various vulnerabilities. Several types of market failures have been identified in the literature that, when addressed with contracts, can help farmers overcome their problems, including: a) access to credit for production inputs; b) price risk and information asymmetry; c) access to profitable markets; and d) product quality[16$18,20,21]$.The most consequential thing is that it can raise the level of integration between smallholders as primary producers and global marketing channels, allowing them to reach a wider market[21].

The benefits of coffee certification are still being discussed, and research findings vary [22-24]. The complexity of standards or attributes in certificates, as well as the contextual elements issues such as market structure to the fidelity of certification implementation, make it difficult to generalize the study's findings $[8,25]$. Small farmers are usually willing to accept a certificate if they consider that participating in the program would give them economic benefits. Usually, small farmers will be willing to accept a certificate if they think that their involvement in the program will increase their level of welfare, even though it gives hope for an increase in welfare, certification is still not considered a fair offer for farmers[26]. Small farmers ability and risk preference, according to Joshi et al. [27], are also crucial elements in explaining their decision take to join in a certification program.

Previous studies have found that improving crop yields is significantly more important than increasing the premium price for increasing the net cash return of farmers' households, hence a certification program is advised to execute a productivity enhancement scheme. Meanwhile, Ruben and Fort[28]found that fair trade certification has a minor impact on the direct income of farmers' households as well as output in their study of farmer participation in fair trade certification. This finding is also supported by Chiputwa et al.[25], which states that a higher selling price does not always lead to an increase in welfare, because the higher price is accompanied by additional costs that must be incurred by farmers to participate in 
certification. Furthermore, production may be reduced due to restrictions or prohibitions on the use of chemical fertilizers, as well as the necessity for additional labour, such as for production that meets certificate standards.

The environmental impact of coffee certification was also investigated by a number of researchers. Previous studies found that the coffee certification program or scheme has good environmental impacts, such as increasing forest density [29], and farmers are becoming more adept at dealing with environmental issues such soil and water conservation, waste management, and the use of pesticides[30].

\subsection{Preferences for accepting contract}

Research on farmers' preferences for coffee certification in Indonesia is still very limited. According to previous studies, several certification attributes affect farmers' preferences on contract farming such as input supply [13,31,32], technical assistance or agricultural training $[10,13,15,31,33]$, quality of product $[10,13,33]$, price options or premium price $[5,10,13,31,33]$, selling agreement [5,10], monitoring [31,34].The following are some studies that can be used as references. Ibnu et al. [5] conducted research on preferences for coffee certification using Conjoint Analysis. The results showed that economic factors were the driving factors for farmers in choosing production contracts, such as the offer of a premium price, the difference in coffee prices between contracts and non-contracts, the difference in the price of coffee beans based on their size and also the offer of assistance in the form of credit. In line with Ibnu, Vermeyen [10] also states that the provision of bonuses and extension services is an important aspect of ensuring the participation of farmers in participating in certification or contract programs, while delayed payments, remote delivery locations, and prohibitions on the use of synthetic chemicals are considered as inhibiting factors for farmers' participating in the contract. Farmers will be more interested to join in a contract or partnership if the contract design incorporates input, technical assistance, and seed supply, according to Abebe et al. [13]the output quality variable and the price option variable are the next two variables to be considered. Economic factors, or motives for enhancing farmers' income or wellbeing, have been demonstrated in several studies to be the primary motivators for farmers to enter contracts.

Meemken et al. [33] conducted a study on farmers' preferences for the design of coffee certification contracts from a gender viewpoint outside of Indonesia. This research also incorporates monetary factors, such as coffee pricing at various levels. The Willingness to Accept [35] estimate is defined in this study as the amount of money required to increase (or decrease) the price per kilogram in order for farmers to choose - or accept - a certification method that incorporates each attribute. According to Valkila[36], two key factors determine the income of certified coffee producers: market pricing and premium prices received by farmers.

Gelaw et al. [37] used a Choice Experiment (CE) approach to investigate farmers' preferences for coffee marketing channels. Personal relationships between farmers and traders are significantly more important than coffee price bids when it comes to picking coffee marketing channels, according to studies. Previous studies have used CE to investigate schema or contract attributes. Meemken et al. [33] stated that farmers dislike attributes that prevent the use of inputs to enhance productivity, such as the use of chemical pesticides and on the other hand, they like attributes benefit them such as agricultural training and female participation in the workforce. Aside from coffee, Permadi et al. [15] used a choice experiment to investigate local communities' preferences for receiving a forestry partnership contract to plant pulpwood in Indonesia, and the findings show that several contract attributes, such as road repair facilities, higher income expectations, and higher timber production insurance, increase local community benefits. 


\subsection{Geographical Indication on coffee}

In comparison to the one-way application of private standards in coffee certification, where farmers are not involved in the formulation of contract or certificate attributes, Geographical Indication appears to be rather different. Local actors who can describe the linkage to the terroir develop the codes of practice for GIs (including the demarcation of the production area as well as a characterization of production standards and quality of product)[38].Meanwhile, Bramley et al. [39] emphasized the importance of consensus in developing a code of practice for the Geographical Indication scheme, where the definition and characteristics of Geographical Indication products must be reflected and embodied in a single code.

Recent studies on the economic benefits of GI schemes are still being discussed [1] and more empirical research is needed to justify [40]. Geographic indications have the greatest potential to benefit small farmers in developing countries, according to Bramley et al. [41], when traditional small-scale production is still in the distribution chain and final products are marketed directly to the consumer. In contrast, due of the risk of failure, Yeung and Kerr [42] do not propose including GI schemes into agricultural development projects in developing countries. Several failures from the implementation of the GI system include: price factors and collective action [43]; GI requirement factors that are not recognized or cannot be accepted somewhere [44]; and the nascent GI concept, so the market reputation is still weak [45].According to Galtier et al.[14], one of the key reasons constraining the development of effective and fair Geographical Indications in the coffee sector is the design of the Code of Practice (CoP), which fails to account the distribution of benefits along the supply chain of GI products.

\section{Method}

Conducting a choice experiment (CE), as demonstrated by Permadi et al.[15], regarding farmers preferences in forestry partnership; and Vermeyen [10] regarding farmers preferences in coffee certification in Uganda, is a method that allows us to express preferences using surveys. A similar approach will be used in this study to study about coffee farmers' preferences for various features of GI's code of practice in Indonesia.

\subsection{Choice experiment approach}

The Choice Experiment (CE) is a technique that uses choice statements to measure individual preferences. Respondents are asked to choose their preferred alternative based on a set of hypothetical scenarios known as the choice set in this method[46]. Many studies have used the $\mathrm{CE}$ approach to investigate contract attributes, such as coffee farmers' preferences for coffee certification [10], contract attribute design [33], farmers' preferences for increasing sustainability in arable land [6] and sustainable farm management contracts [19]. Individuals are expected to choose one option that maximizes the utility or satisfaction of each alternative package presented to them when CE is implemented. Respondents or individuals who are the subject of study indirectly imply that selecting one of the alternatives presented will provide them with more benefits or utility [10]. The factors that determine respondents' choices can be observed, although it is possible that other unobserved factors can also influence respondents in making their choices. Random Utility Model was used to observe the factors in the modelling, which were then analysed using a discrete choice model. Referring to Bateman et al. [47] which is also used by Permadi et al. [15], RUM is expressed in the following equation : 


$$
U_{i j}=V_{i j}+\varepsilon_{i j}
$$

Where $U$ can be explained as respondent utility $(i)$ choosing alternative options $(j)$, and $V i j$ is the systematic (observable) utility, while $\varepsilon_{i j}$ is the random (unobservable) utility which explains factors that are not observed when respondent chooses an alternative. The deterministic component which is the observable utility is then explained into the following Conditional Logit Model equation:

$$
V i j=\beta X_{i j}+\varepsilon_{i j}
$$

$X_{i j}$ in this equation explain the various predictors, $\beta$ is the estimated parameters that show how a certain variable affects the observed willingness to accept GI's scheme and $\varepsilon_{i j}$, is the model's error term, which is considered to be Gumbel distributed. The implicit price in the equation model above is calculated using the following formula:

$$
W T A P=\beta n / \beta m
$$

where $(\beta \mathrm{n})$ is a non-monetary attribute and $(\beta \mathrm{m})$ is a monetary attribute, which in this study is an additional premium price. A positive value means that the respondent has a willingness to pay where an increase in the level of non-monetary attributes increases utility. Conversely, a negative value is defined as a willingness to accept (Willingness to Accept), where the higher the non-monetary attribute, the greater the compensation that

\begin{tabular}{|c|c|}
\hline Attribute & Attribute Level \\
\hline Pesticide (Pes) & $\begin{array}{l}\text { 1. Not allowed } \\
\text { 2. Allowed }\end{array}$ \\
\hline Harvesting (Harv) & $\begin{array}{l}\text { 1. Less selective picking (Ripe berries }<95 \% \text { ) } \\
\text { 2. Selective picking (Ripe berries }>95 \% \text { ) }\end{array}$ \\
\hline Coffee Processing (Proc) & $\begin{array}{l}\text { 1. Full Washed } \\
\text { 2. Natural } \\
\text { 3. Dry Process } \\
\text { 4. Honey Process }\end{array}$ \\
\hline Selling Agreement $(S A)$ & $\begin{array}{l}\text { 1. Contract } \\
\text { 2. No Contract }\end{array}$ \\
\hline Monitoring (Monit) & $\begin{array}{l}\text { 1. Willing to be monitored } \\
\text { 2. Not willing to be monitored }\end{array}$ \\
\hline $\begin{array}{l}\text { Technical Assistance } \\
\text { (Assist) }\end{array}$ & $\begin{array}{l}\text { 1. Not Provided } \\
\text { 2. Provided (Group training once a year) } \\
\text { 3. Provided (Group training onece a year }+ \text { regular } \\
\text { individual assistance }\end{array}$ \\
\hline $\begin{array}{l}\text { Additional Premium Price } \\
\text { of Green Beans (Price) }\end{array}$ & $\begin{array}{l}\text { 1. Market price } \\
\text { 2. Market price + IDR } 10,000 / \mathrm{kg} \\
\text { 3. Market price + IDR } 20,000 / \mathrm{kg} \\
\text { 4. Market price + IDR } 30,000 / \mathrm{kg} \\
\text { 5. Market price + IDR } 40,000 / \mathrm{kg}\end{array}$ \\
\hline
\end{tabular}
will be received by the respondent.

Table 1. Description of scheme attributes and level with status quo levels in bold

Source: Own elaboration based on $[10,30]$

\subsection{Survey design and generate choice sets}

The design of choice sets refers to Aizaki and Nishimura [48], a) creating a full factorial design; b) creating a fractional factorial design; c) creating a copy of the fractional factorial design; d) creating choice sets using random selection without replacement; and d) translating the code. We used R software to generate 14 choice sets based on the selected 
attributes and attribute levels, which are presented in Table 1. Each choice set consists of two alternative options (option 1 and Option 2) with reasonable combinations and different attribute levels. Each choice set has two proposed alternative GI's scheme (option 1 and option 2) with plausible combinations of different attribute levels. One alternative option is added (option 3) to each set of options, which is the farmer's choice opt out neither options 1 or 2 (status quo). The 14 choice sets were divided into two blocks, so that in the survey, respondents only answered seven choice sets. To make data collection easier, a choice card was designed for respondents to answer every single of choice set given to respondent. Choice cards are made as attractive as possible by adding pictures that make it easier for respondents to understand the choices offered. For example, the selection card can be seen in Table 2.

Table 2. Example of choice card

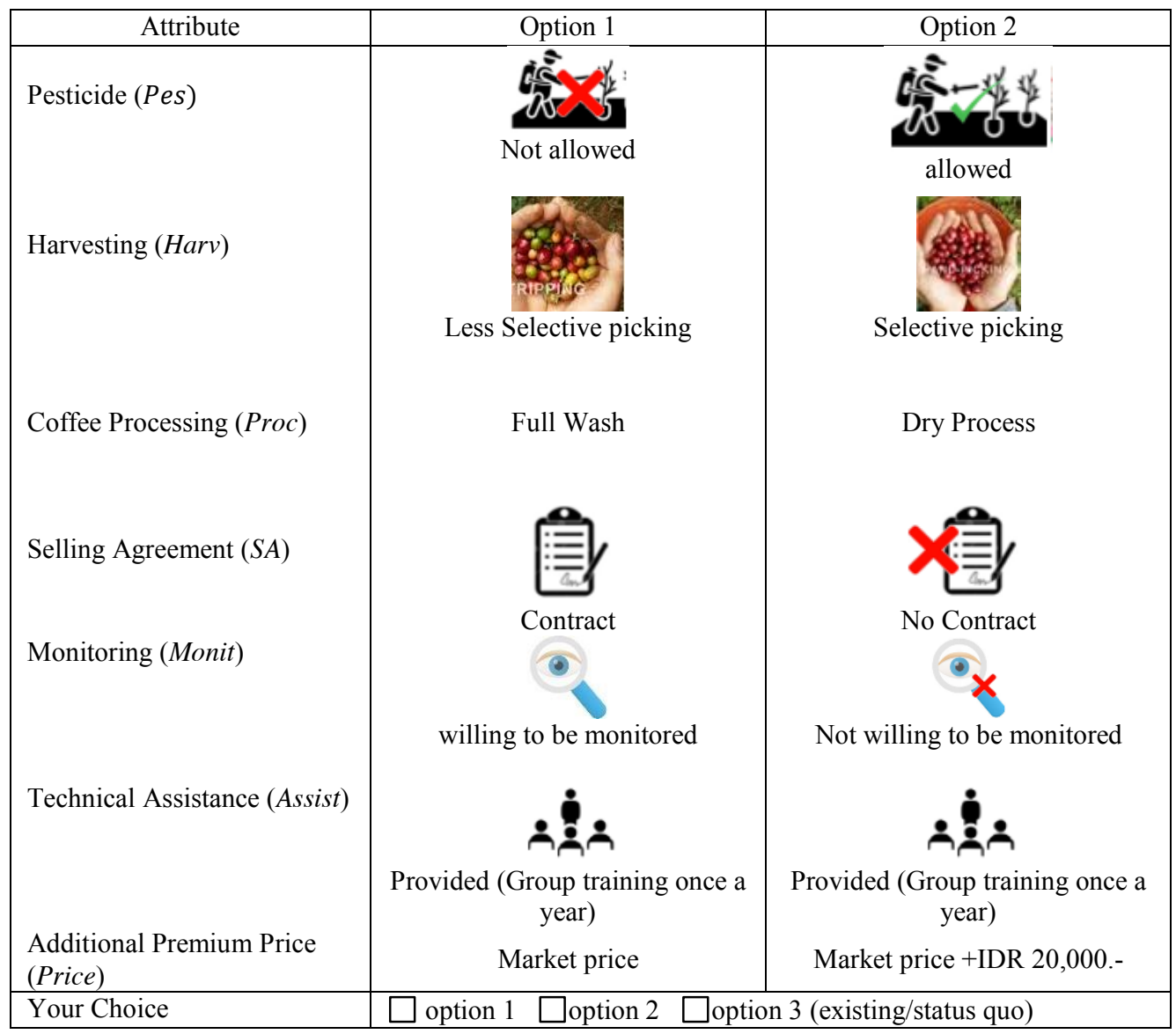

\subsection{Sample and data collection}

The survey in this study was conducted on 157 farmers spread over 5 sub-districts in the Geographical Indications of Temanggung Robusta Coffee (KRT) located in Temanggung Regency, Central Java Province, which is also a coffee production central in Central Java (Figure 1). The five sub-districts are Candiroto, Bejen, Gemawang, Kandangan and Kranggan. The research location is in the lowlands ranging from an altitude of 458 meters to 680 meters above sea level. The convenience sampling technique was used in this 
survey, which allowed us to collect respondents who could and were judged to be able to cooperate with surveyor in this research survey[49]. Interviews were conducted face-toface, using Javanese and Indonesian language, from November 2020 to February 2021.

\subsection{Data analysis}

The following equation represents the whole model using conditional logit model:

$$
\begin{aligned}
& V_{n j t}=A S C+\beta_{1} \text { Pes }_{1_{n j t}}+\beta_{2} \text { Pes }_{2_{n j t}}+\beta_{3} \operatorname{Harv}_{1_{n j t}}+\beta_{4} \operatorname{Harv}_{2_{n j t}}+\beta_{5} \text { Proc }_{1_{n j t}}+ \\
& \beta_{6} \text { Proc }_{2_{n j t}}+\beta_{7} \text { Proc }_{3_{n j t}}+\beta_{8} \text { Proc }_{4_{n j t}}+\beta_{9} S A_{1_{n j t}}+\beta_{10} S A_{2_{n j t}}+\beta_{11} \text { Monit }_{1_{n j t}}+ \\
& \beta_{12} \text { Monit }_{2 n j t}+\beta_{13} \text { Assist }_{1_{n j t}}+\beta_{14} \text { Assist }_{2 n j t}+\beta_{15} \text { Assist }_{3_{n j t}}+\beta_{16} \text { Pr ice }_{1_{n j t}}+ \\
& \beta_{17} \operatorname{Pr}_{i c e_{2 n j}}+\beta_{18} \operatorname{Pr} i c e_{3_{n j t}}+\beta_{19} \operatorname{Pr}_{i c e_{4} j t}+\beta_{20} \operatorname{Pr}_{i c e_{5} j t}+\varepsilon_{n j t}
\end{aligned}
$$

Where $n$ is specific respondent, $\mathrm{j}$ is alternative specific, $\mathrm{t}$ is choice set and $\beta$ is respondent's preference for attribute level, which is defined as the value of the choice set of estimation that minimizes the difference between observations in the data and the estimated model (sum of squared residuals) [50]. The Alternative Specified Constant (ASC) in the model indicates the opt out option (not choose Geographical Indication scheme). ASC is a dummy variable with a value of 1 for choosing the status quo option, and 0 for choosing IG's scheme [51].Based on the above equation, it can be explained that $V_{n j t}$ is the probability of choosing one profile (a combination of attributes and levels) from the total of all profiles simultaneously. The above model assumes that the probability of selecting a profile is a linear function of the attribute level in the profile. To identify the factors that influence farmers' preferences to choose the 'opt out' scheme offered, we examine the interaction of ASC with farmers' socio-economic variables (Table 3).

Table 3. Respondent characteristics

\begin{tabular}{|l|r|r|r|r|}
\hline Respondent Characteristics & \multicolumn{1}{|c|}{ Mean } & \multicolumn{1}{c|}{ Std. Dev. } & \multicolumn{1}{l|}{ Min } & \multicolumn{1}{l|}{ Max } \\
\hline Number of Respondents & 157 & & & \\
\hline Age (year) & 47.8 & 10.3 & 23.0 & 70.0 \\
\hline$>45(63.69 \%)$ & & & & \\
$\geq 60(14.01 \%)$ & 3.8 & 1.2 & 1.0 & 7.0 \\
\hline Family Size (people) & 1.0 & 0.9 & 0.0 & 5.0 \\
\hline Farm size (ha) & & & & \\
\hline$<1$ ha (54.78\%) & 8.9 & 3.6 & 0.0 & 19.0 \\
\hline Education (year) & & & & \\
\hline No education (1.27\%) & & & & \\
\hline Elementary school (41.40\%) & & & & \\
\hline Junior high school (21.66\%) & & & & \\
\hline High school (28.03\%) & 17.5 & 10.7 & 1.0 & 50.0 \\
\hline Undergraduate (7.64\%) & 24.2 & 13.5 & 4.0 & 80.0 \\
\hline Experience (year) & 2.3 & 0.8 & 1.0 & 5.0 \\
\hline Plant age (year) & & &
\end{tabular}

As presented in Table 3, most of the respondents in the research location is over 45 years old $(63.69 \%)$ with an average of 8.9 years of formal education and an average of 17.5 years of farming experiences. Most of the respondents graduated from elementary school $(41.40 \%)$. Low levels of education could be a constraint in the adoption of technology as well as in the application of agricultural production schemes. The characteristics of farmers in the study location is dominated by coffee farmers who own coffee plantation of less than 
1 ha $(54.78 \%)$ with an average age of 24.2 years of coffee plants, it is known that coffee plantations in Temanggung have been established since colonial times. The life span of coffee plantations can be more than 20 years [52], even up to 50 years [53].

\section{Results and Discussion}

\subsection{Preferences for accepting Gl schemes}

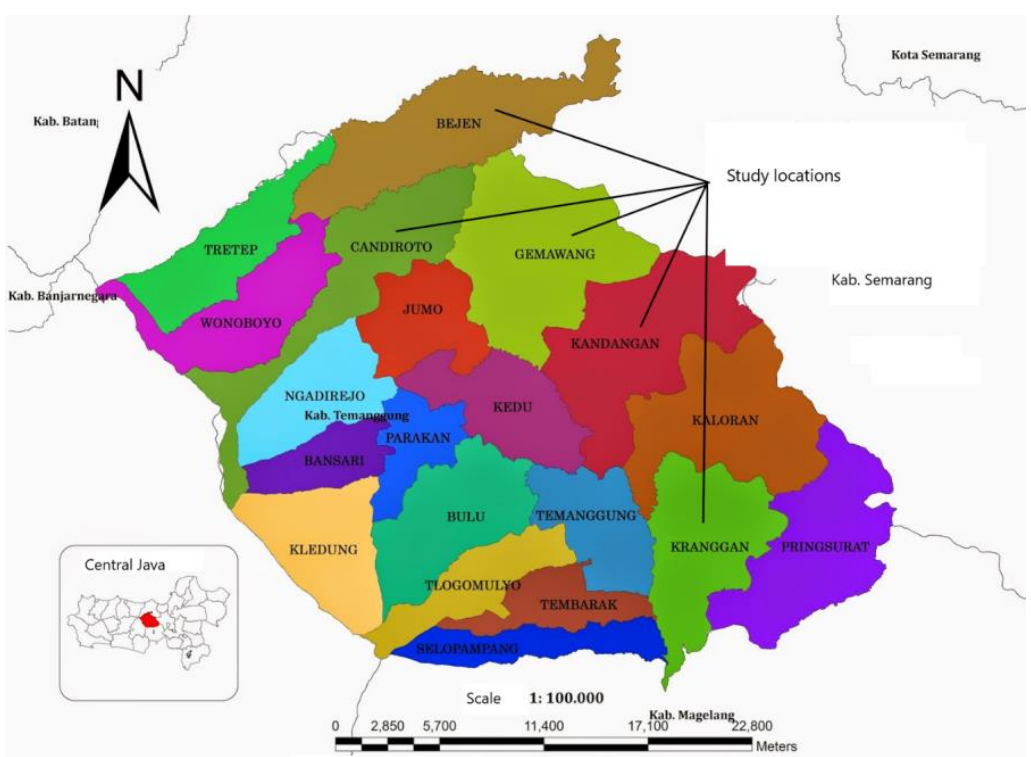

Fig. 1. Map of Temanggung and Study Locations

As presented in Table 4, finding shows that respondents at the research location significantly preferred accepting the GI schemes depending on the attributes of pesticides and monitoring (both are negative), where respondents prefer the GI scheme which does not prohibit the use of pesticides and also does not implement the monitoring of GI standards. The negative value for both attributes indicated that compensation is required by local farmers to accept the standards of pesticide and monitoring.

The Odds ratio of Pes (the use of pesticides) indicated that the probability preferring GI schemes by respondents would decrease $58 \%$, as respondents accepting GI schemes rather than status quo (pesticide allowed). The use of attributes pesticide in the GI scheme is still an obstacle for farmers to accept the GI scheme. The findings in this study are in line with the results of previous studies which stated that a negative preference for prohibiting the use of pesticides is plausible and is an obstacle for farmers to participate in contract schemes $[10,33,36]$. Meemken et al. [33], in a study on the design of a coffee certification scheme in Uganda, stated that the prohibition of pesticides can result in the duration of time for coffee farmers to clear grass and can also result in a decrease in crop yields. While Jena et al.[54] stated that the limited availability of organic pesticide (including bio herbicides) is the main obstacle for farmers implementing prohibition of pesticides use standard in certified coffee. Bans on pesticide use attribute in certified coffee in several countries also encountered several obstacles, including the lack of knowledge of farmers about the contract schemes offered [5]. 
For the attribute monitoring, the odds ratio is 0.603 , which implies that one unit increase in the attribute would decrease the probability of selecting GI schemes by $60.3 \%$. The finding shows that farmers in the study locations tend to avoid inspections and supervision regarding of the implementation of GI schemes. In line with our findings, Hung Anh [31] discovered that monitoring attributes had a negative impact on coffee farmers' participation in contract farming. Monitoring aims to minimize the risk of uncertainty of supply and quality of product and has no major impact on farmers' responsibilities in production and farming practice, according to Glover and Kusterer [55]. Several factors may influence respondents' negative preferences for monitoring attributes, including the experience factor and also the education factor where most of the farmers only graduated from elementary school $(41.40 \%)$ and most of them are more than 45 years old $(63.69 \%)$.

Furthermore, farmers' choices are positively related to the attributes of Proc (coffee processing), SA (selling agreement), and Assist (technical assistance). Based on the positive value of the Proc and Assist attributes, it implies that farmers are willing to pay for each attribute level that increases. While the positive value on the SA attribute indicates that the farmer wants a selling agreement between the farmer and the MPIG. The marginal effect of the Proc and SA variable shows that the probability of accepting GI schemes would increase 1.104, 5.484 and 1.305 times respectively, as one-level increase in Proc, SA and Assist.

Table 4. Model estimates and part-worth of Conditional Logit Model

\begin{tabular}{|c|c|c|c|c|c|c|}
\hline Variable & Coeff. $(\beta)$ & Std. Err. & $\mathbf{z}$ & $\mathbf{P}>|\mathbf{z}|$ & Odds Ratio & Mean WTP \\
\hline$A S C$ & $15.324 * * *$ & 3.324 & 4.610 & 0.000 & & 265.860 \\
\hline Pes & $-0.544 * * *$ & 0.133 & -4.090 & 0.000 & 0.580 & -9.851 \\
\hline Harv & 0.135 & 0.117 & 1.160 & 0.246 & 1.145 & 2.557 \\
\hline Proc & $0.099 *$ & 0.053 & 1.840 & 0.065 & 1.104 & 1.693 \\
\hline$S A$ & $1.702 * * *$ & 0.185 & 9.180 & 0.000 & 5.484 & 29.577 \\
\hline Monit & $-0.506 * * *$ & 0.127 & -3.990 & 0.000 & 0.603 & -9.077 \\
\hline Assist & $0.266^{* * *}$ & 0.065 & 4.080 & 0.000 & 1.305 & 4.625 \\
\hline Price & $0.058 * * *$ & 0.003 & 17.100 & 0.000 & 1.059 & \\
\hline ASC x Age & $-0.092^{*}$ & 0.051 & -1.790 & 0.074 & 0.913 & \\
\hline ASC xhh size & $-0.701 * *$ & 0.328 & -2.140 & 0.033 & 0.496 & \\
\hline ASC x farm size & $-0.935^{*}$ & 0.388 & -2.410 & 0.016 & 0.392 & \\
\hline ASC $x$ Coop status & -0.377 & 0.900 & -0.420 & 0.675 & 0.617 & \\
\hline Number of obs & 3276.000 & & & & & \\
\hline $\mathrm{Nr}$ of resp & 157.000 & & & & & \\
\hline Prob $>$ chi 2 & 0.000 & & & & & \\
\hline Pseudo R2 & 0.391 & & & & & \\
\hline Log likelihood & -730.650 & & & & & \\
\hline \multicolumn{7}{|c|}{$*$ significance at $<10 \%$} \\
\hline \multicolumn{7}{|c|}{$* *$ Significance at $<5 \%$} \\
\hline \multicolumn{7}{|c|}{$* * *$ Significance at $<1 \%$} \\
\hline
\end{tabular}

Positive preference results on coffee processing (Proc) attributes indicate that the existing conditions of farmers comply the standard of the GI scheme in term of coffee processing. There are three processing procedures refer to Geographical Indication Requirements book of KRJ, 1) dry process; 2) honey process; and 3) full washed process. In term of dry process, there are two procedures can be applied. First, cherries are drying without coffee skin removing and second, cherry drying with removing coffee skin. The attribute level compiled in this study distinguishes between the two procedures of dry process by using the term Natural process to describe drying without removing the coffee skin and dry process to describe drying by removing the coffee skin. An increased attribute 
level can be interpreted as an increase in processing duration which results in an increase in workforce. An increase in the attribute level also shows an increase in production costs. The more farmers choose a higher attribute level, in this case the highest is full washed process, then the farmer will require a longer time, more labour, and higher costs than the process at a lower level (for example the use of water for washing).

In term of the attribute of SA (Selling Agreement), We expect a negative preference for this attribute, as in previous finding by Ibnu et al.[5], where farmers prefer not to have a formal contract with the buyer because they want to maintain their social relationship with the buyer or they can freely sell to other buyers and see opportunities for higher prices if there is no formal contract with the buyer. A Positive preference and significant (1\%) in our study, could be explained that farmers want certainty of purchase if they apply for the GI scheme. The existing GI scheme does not cover the implementation of the selling agreement. However, in the future, MPIG can develop cooperatives that would be able to purchase coffee from farmers who are members of MPIG with an agreed price scheme.

Furthermore, regarding Assist variable (technical assistance), respondents prefer more intensive technical assistance, such as that offered by the scheme in the form of group and individual technical assistance, to help them implement the GI standard. Technical support in contract farming can drive coffee producers to increase farm performance while also having a positive impact on their knowledge and farming experience [13,31]. Inaccessibility to technical assistance is a common issue that can stymie farmers' efforts to increase productivity and render them unable to deliver the number and quality of products that they expect [31].

Similarly, the Price variable also has a positive and significant effect on farmer preference for GI schemes, with a marginal effect value of 1.059 , which means that for every one-level increase in premium price, the probability of farmers accepting a GI scheme increases 1.059 times. The price estimation for processed coffee is as expected where producers tend to choose higher. Positive Price signals could be explained by higher quality green beans, which will lead to an increase in prices. Respondents prefer to sell at higher price could be explained as most of them have to be selective picking only ripe cherries. Coffee cherries that are picked selectively are likely to have a higher price than coffee cherries that are picked less selectively. The same finding in terms of the premium price attribute in contract farming was reported by Ibnu et al.[5], where this attribute positively and significantly affected farmers' preference for participating in a contract.

IG coffee certification, on the other hand, might be classified as an informal contract farming model in the absence of a written price agreement. Because the pricing system is flexible and depends on the local spot market price, it is sometimes just a verbal contract that can causes the risk of loss[56]. Different result shown in the previous study conducted by Abebe et al.[13], where farmers prefer not to be locked into a fixed price agreement due to underpayment concerns, and this caused barrier for the farmers participating in contract farming.

The results of previous study related to coffee certification show that farmers who participate in coffee certification schemes, such as the Fairtrade certification, get a premium price because the certification program is able to reduce the intermediaries' market power [57]. Meanwhile, Barham and Weber [58] stated that the price attribute is not more important than a certification scheme that is able to increase coffee yields due to high yields, which will increase the net cash return for coffee farmers. A scheme that is able to increase crop yields will be able to increase farmers' income and be able to keep farmers from participating in the certification scheme. The price attribute in certification is the main draw for farmers to participate, but due to the volatile nature of coffee prices, the premium price attribute may be ineffective in the certification scheme. 
Furthermore, as seen in Table 4, negative signal of part-worth values reflects the respondent's willingness to accept compensation (WTA) for participating in the offered schemes, whereas a positive sign shows the respondent's willingness to pay (WTP) for the change. As shown in Table 4, the negative sign on the Pesticide attribute indicates that the change from the farmer's existing condition from being free to use pesticides to the GI schemes where the use of pesticides is not allowed requires compensation (WTA) IDR 9,851 , and for the willingness of farmers to accept monitoring attributes, compensation is required (WTA) IDR 9,077. Furthermore, respondents were WTP IDR 1,693, IDR 29,577 and IDR 4,625 for better Proc, choosing SA and better Assist, respectively. Respondents who prefer not to choose GI schemes, can be explained from the positive signals of ASC. Respondents is willingness to pay for opt out option IDR 265,859 .

\subsection{Socio-economic aspects affecting GI schemes rejection}

ASC, as presented in Table 4, reflects the respondents' choice of the opt out option (status quo). It can be defined as a situation in which farmers choose to produce coffee under market conditions without the use of GI schemes. The ASC estimate is significant, demonstrating that farmers are concerned about whether they accept GI schemes or not. According to Permadi et al.[15], the positive value of ASC indicates "an underlying preference for abandoning the contract in the future".

The sign of the ASC can be used to interpret the relationship between ASC and farmers' socio-economic characteristics, as illustrated in Table 4. According to the model, the farmer's age, the number of family members, and the size of the farm can all play a significant role in their decision not to accept the GI scheme. While the farmer's option to opt out is unaffected by his or her membership in a cooperative. The ASC interaction with the age factor is negative, indicating that the older the farmer, the higher the probability of choosing the GI scheme option offered. Likewise, with the land area factor, a negative value indicates that the larger the land owned by the farmer, the higher the probability of choosing GI schemes. The interaction between ASC and family size is also negative, implying that the number of family members influences farmers' decisions to accept the GI scheme. The more family members, which can also be interpreted as the more family labour, the lower the probability of farmers opting out. Like previous study on contract farming, the selection of farmers to opt out the forestry partnership contract was negatively and significantly explained by age, family size and farm size [15]; age and farm size [13].

\subsection{Increasing participation in GI scheme strategy}

Several strategies can be applied based on the results of this study to involve more farmers in GI-based coffee production schemes. Therefore, efforts need to be made to maximize the effects of positive attributes and minimize the effects of negative attributes[15]. Minimizing the negative effects of Pes attributes can be done by providing education and socialization to farmers about environmentally friendly agriculture. In the same way, farmers must also be given an understanding of the importance of monitoring and supervision, so that the quality of the coffee beans produced meets GI quality standards. In addition, there is an attribute in the developed model that is not significant, which is the Harvest attribute (selective picking). As is known, one of the main standards for coffee processing that meets the GI standard is that coffee is picked only when it is ripe, so selective picking is necessary. In practice, however, many farmers remain opposed to selective picking, possibly because it requires more time and money or because of late factors in the picking process. 
Our findings show that farmers have expressed a significant willingness to get technical assistance as a "bonus" earned when participating in the GI scheme and also show a significant motivation to process coffee according to GI standards. Stakeholders, both governments and MPIG institutions, can play an important role in encouraging farmers to follow a Geographical Indication-based coffee production scheme. The government can help strengthen MPIG institutions by providing access to credit based on farmer membership in MPIG, building infrastructure, especially those that support facilities and infrastructure for coffee production based on geographical indications, and assisting in the marketing process of GI-based coffee for export purposes. MPIG and the government can play a joint role in increasing farmers' knowledge and understanding of GI-based coffee production schemes. Agricultural extension and training can also be carried out by both the government and MPIG to improve farmers' farming practices so that quality coffee beans are obtained.

Redesigning the GI standard implementation scheme can be used as one of the strategies. According to the findings of this study (see Table 4), some attributes, such as Pes (pesticide use) and Monit (monitoring and supervision), have a negative effect on the likelihood of respondents choosing the GI scheme. Modifications in the design of attributes can be done, for example by applying a price difference policy based on the grade of coffee. Research conducted by Ibnu et al.[5] and Abebe et al.[13] shows that the price differences based on coffee size as one of the attributes in the contract farming scheme can have a positive effect on farmers' willingness to participate.

\section{Conclusions and Suggestion}

This research contributes to addressing one of the challenges in establishing GI programs that continues to obstruct the implementation of the GI scheme for coffee commodities in Indonesia which is the lack of control over the GI Code of Practice's implementation (Neilson et al., 2018). GI Certification emphasizes the importance of consensus in developing a code of practice for the Geographical Indication scheme by involving all stakeholders, including farmers, processors, traders, MPIG, and the government, in contrast to private certification schemes whose schemes are prepared by certification applicants. Low participation in the GI scheme might be caused by the design of a scheme that does not take into consideration the preferences of farmers as the main players. The Code of Practice for the GI scheme has both a benefit and a requirement attribute.

Based on Conditional Logit Model (CLM), the study shows that small farmers dislike attributes that prohibit them from using pesticides and also prefer no monitoring and supervision in the implementation of the GI scheme. Nonetheless, small farmers were positively influenced by the attributes of coffee processing, selling agreement, technical assistance, and additional premium prices to adopt the GI scheme, implying their willingness to pay for scheme attributes.

This study suggests that MPIG might take an educational approach to monitoring and supervising the GI scheme's implementation so that farmers can apply GI standards properly. Furthermore, this study also suggests that MPIG and local government should work to educate farmers' understanding of ecologically friendly agriculture practices such as using organic pesticides. It is hoped that the use of bio-pesticides will assist farmers in making the transition from highly toxic conventional chemical pesticides to fully sustainable agriculture. 


\section{Reference}

1. J. Neilson, J. Wright, and L. Aklimawati, Journal of Rural Studies 59, 35 (2018).

2. J. Neilson, Bulletin of Research on Spice and Industrial Crops 4, 183 (2013).

3. L. Menapace, G. Colson, C. Grebitus, and M. Facendola, Iowa State University, Department of Economics, Staff General Research Papers (2009).

4. J. Sarwono, Jurnal Ilmiah Manajemen Bisnis 10, 173 (2010).

5. M. Ibnu, P. Glasbergen, A. Offermans, and B. Arifin, Journal of Agricultural Science 7, 20 (2015).

6. M. De Salvo, G. Cucuzza, S. Cosentino, L. Nicita, and G. Signorello, New Medit XVII, 57 (2018).

7. M. Adnyana and P. Wardana, Jurnal Penelitian Pertanian Tanaman Pangan 35, 53 (2016).

8. C. Oya, F. Schaefer, and D. Skalidou, World Development 112, 282 (2018).

9. W. Bekele, African Development Review 18, 183 (2006).

10. V. Vermeyen, KU Lueven, 2017.

11. I. K. Ardana, Agricore 2, 242 (2017).

12. D. Giovannucci and S. Ponte, Food Policy 30, 284 (2005).

13. G. K. Abebe, J. Bijman, R. Kemp, O. Omta, and A. Tsegaye, Food Policy 40, 14 (2013).

14. F. Galtier, G. Belletti, and A. Marescotti, Development Policy Review 31, 597 (2013).

15. D. B. Permadi, M. Burton, R. Pandit, D. Race, and I. Walker, Forest Policy and Economics 91, 73 (2018).

16. P. Vlaeminck, L. Vranken, G. Van den Broeck, K. Vande Velde, K. Raymaekers, and M. Maertens, Farmers' preferences for Fair Trade contracting in Benin, 2015.

17. S. J. Väth, S. Gobien, and M. Kirk, Land Use Policy 81, 878 (2019).

18. S. Fischer and M. Wollni, Food Policy 81, 67 (2018).

19. J. M. Duke, A. M. Borchers, R. J. Johnston, and S. Absetz, Ecological Economics 74, 95 (2012).

20. R. Nandi, N. Gowdru, and W. Bokelmann, 5, 178 (2018).

21. G. Ton, W. Vellema, S. Desiere, S. Weituschat, and M. D'Haese, World Development 104, 46 (2018).

22. H. Hansen and N. Trifković, World Development 56, 226 (2014).

23. J. C. Beghin, M. Maertens, and J. Swinnen, Annual Review of Resource Economics 7, 425 (2015).

24. K. Vanderhaegen, K. T. Akoyi, W. Dekoninck, R. Jocqué, B. Muys, B. Verbist, and M. Maertens, Global Environmental Change 51, 1 (2018).

25. B. Chiputwa, D. J. Spielman, and M. Qaim, World Development 66, 400 (2015).

26. C. B. Barrett, M. E. Bachke, M. F. Bellemare, H. C. Michelson, S. Narayanan, and T. F. Walker, World Development 40, 715 (2012).

27. P. Joshi, A. Kumar, and A. Dsouza, Applied Economic Perspectives and Policy 40, 353 (2018).

28. R. Ruben and R. Fort, World Development 40, 570 (2012).

29. R. Takahashi and Y. Todo, World Development 92, 158 (2017).

30. E. Giuliani, L. Ciravegna, A. Vezzulli, and B. Kilian, World Development 96, 294 (2017).

31. N. Hung Anh, W. Bokelmann, N. Thi Thuan, D. Thi Nga, and N. Van Minh, Sustainability 11 (2019).

32. M. Prowse, Contract farming in developing countries - a review 2012).

33. E.-M. Meemken, P. Chellattan Veettil, and M. Qaim, Small farmers' preferences for the design of certification schemes: Does gender matter? 2016. 
34. A. Arouna, P. Adegbola, B. O, and A. Diagne, Contract farming preferences of smallholders rice producers in Africa: a stated choice model using mixed logit 2015).

35. M. O. A. Manikmas, Indonesian Journal of Agricultural Science; Vol 13, No 2 (2012): October 2012 (2012).

36. J. Valkila, Ecological Economics 68, 3018 (2009).

37. F. Gelaw, S. Speelman, and G. Van Huylenbroeck, Food Policy 61, 92 (2016).

38. F. Galtier, G. Belletti, and A. Marescotti, (2008).

39. C. Bramley, E. Biénabe, and J. Kirsten, The Economics of Intellectual Property (2009).

40. P. R. Jena and U. Grote, Development Policy Review 28, 217 (2010).

41. S. Bolwig, P. Gibbon, and S. Jones, World Development 37, 1094 (2009).

42. M. T. Yeung and W. A. Kerr, The Journal of World Intellectual Property 14, 353 (2011).

43. A. Tregear, Á. Török, and M. Gorton, Environment and Planning A: Economy and Space 48, 433 (2015).

44. S. Bowen, Rural Sociology 75, 209 (2010).

45. C. Durand and S. Fournier, World Development 98, 93 (2017).

46. C. Vass, D. Rigby, and K. Payne, Medical Decision Making 37, 298 (2017).

47. I. J. Bateman et al., Economic Valuation with Stated Preference Techniques: A Manual (Edward Elgar, UK, 2002).

48. H. Aizaki and K. A Nishimura, Agricultural Information Research 17, 86 (2008).

49. J. C. Welman and F. Kruger, Research methodology for the business and administrative sciences (Oxford University Press, Cape Town; Oxford, 2002).

50. A. B. Hauber, J. M. González, C. G. M. Groothuis-Oudshoorn, T. Prior, D. A. Marshall, C. Cunningham, M. J. Ijzerman, and J. F. P. Bridges, Value in Health 19, 300 (2016).

51. C. Schipmann and M. Qaim, Food Policy 36, 667 (2011).

52. ICC, (International Coffee Organization, London, 2016).

53. Worldbank, (1982).

54. P. R. Jena, T. Stellmacher, and U. Grote, Environment, Development and Sustainability 19, 45 (2017).

55. D. S. Glover, Small farmers, big business: contract farming and rural development /David Glover and Ken Kusterer (Macmillan, Houndmills, Basingstoke, Hampshire, 1990), Macmillan international political economy series, Accessed from https://nla.gov.au/nla.cat-vn1755870.

56. C. Eaton and A. W. Shepherd, (Food \& Agriculture Organizaation, Rome, Italy, 2001).

57. A. Podhorsky, Journal of Development Economics 116, 169 (2015).

58. B. L. Barham and J. G. Weber, World Development 40, 1269 (2012).. 